BEHAVIOR THERAPY 19, 283-300, 1988

\title{
On the Range of Cognitive Plasticity in Old Age as a Function of Experience: 15 Years of Intervention Research
}

\author{
Paul B. Baltes \\ ULMAN LINDENBERGER \\ Max Planck Institute for Human Development and Education, Berlin, FRG
}

\begin{abstract}
Fifteen years of cognitive research conducted by the first author and his colleagues are summarized. This research has shown that many older adults have the reserve capacity to improve their performance on tests of intelligence and other indicators of cognitive efficacy. Improvement results both from self-guided learning and trainer-guided training in relevant cognitive skills. At the same time, there is increasing evidence that there are aging-related limits in the level of training-based performance attainable through practice and other strategies of cognitive engineering. Near maximum limits of capacity, aging loss seems less subject to reversibility. The nature of cognitive aging, thus, involves a Janus-like character: continued plasticity accompanied by increasing limits to plasticity. As programs for the redesigning of the aging process are considered, plasticity and limits to plasticity deserve equal attention in order to reflect the possible strengths and weaknesses of older persons. A model derived from such a dual perspective is presented in the form of selective optimization with compensation.
\end{abstract}

The purpose of this article is to summarize a research program on cognitive plasticity in old age conducted over the last fifteen years by the first author in collaboration with several colleagues. In the first part, the empirical body of data is described as it evolved since the original studies were initiated in the early 1970s. This line of research had as its primary focus the demonstration of plasticity (modifiability). In the second part, recent and ongoing research is summarized. In that line of research the focus has moved from the mere demonstration of plasticity (modifiability) in old age to the study of the limiting conditions (constraints) on plasticity.

The first author expresses his respect and gratitude to the many colleagues who cooperated with him in developing and implementing the research agenda described in this paper. Historically, S. L. Willis deserves special credit as she is the one with whom the first major research project (funded by the U.S. National Institute on Aging) was launched. Address correspondence to: Paul B. Baltes, Max Planck Institute for Human Development and Education, Lentzeallee 94, 1000 Berlin 33, Federal Republic of Germany. 


\section{Historical Background}

A major reason for the initiation of this research program was the general theoretical scenario of gerontological work. The dominant focus of gerontological research during the 1960 s was on aging as a process of universal, cumulative, and gradual decline. As Kastenbaum (1968) observed at the time: Psychological gerontologists seemed to be satisfied with "counting and classifying the wrinkles of aged behavior." There was not much impetus to study conditions and ways by which the aging process could be "redesigned."

As an effort at correcting this deficit and very much stimulated by the emphasis on modifiability in other quarters of psychology (such as operant psychology and behavior modification), the first author in collaboration with a cohort of colleagues (e.g., Margret Baltes, William Hoyer, Gisela LabouvieVief, John R. Nesselroade, and Sherry Willis) set out to outline a research agenda. This agenda was aimed at exploring the degree to which cognitive aging was modifiable as a function of experiential life conditions. Beginning in the early 1970s, a program of intervention research to study the range of modifiability (soon to be labelled "plasticity") of cognitive aging was started.

The general theoretical significance of gerontological intervention work was highlighted in a symposium publication edited by Baltes (1973) with contributions by Looft, Labouvie-Vief, Sparks, Hoyer, Gottesman, Peterson, Schaie, and Charles. For the specific topic of cognitive aging, three theoretical articles (Baltes \& Labouvie, 1973; Baltes \& Schaie, 1976; Labouvie, Hoyer, M. Baltes, \& Baltes, 1974) served as conceptual position papers. Since then, similar orientation papers have appeared, restating, redefining, and elaborating the original frame of reference (e.g., Baltes, 1987; Baltes, Dittmann-Kohli, \& Dixon, 1984; Baltes \& Kliegl, 1986; Kliegl \& Baltes, 1977; Willis, 1985; Willis \& Baltes, 1980). Other researchers, of course, have advanced comparable arguments and stressed the role of intervention research (Denney, 1979, 1984; Kausler, 1982; LabouvieVief, 1977, 1985; Salthouse, 1985). In our view, however, none - for better or worse - has promoted with equal consistency and fervor the strategy of intervention work as the royal road toward understanding the conditions and variations of the nature of cognitive aging.

In what follows, intervention research conducted by us on intellectual performance in late adulthood and old age will be organized around two historically ordered phases: (1) training of cognitive skills associated with intelligence test performance; and (2) training of basic intellectual functioning toward maximum limits of capacity. The summary will be restricted to empirical studies in which the senior author of this article was involved as a researcher. A concluding section is aimed at evaluating the evidence in the context of current conceptions about plasticity in cognitive development and models of how "successful" aging can be engineered.

\section{Phase 1: Training of Performance in Tests of Fluid Intelligence}

\section{Precursor Studies and Framework}

Two studies can be seen as precursor studies to what was later to become the research agenda of Phase 1 . These two precursor studies dealt with the 
modifiability of the speed of test-taking behavior in the context of tests of intelligence.

Specifically, the speed of performing the necessary manual tasks to answer items of intelligence tests was the target of our initial efforts at behavior modification (F. Hoyer, Hoyer, Treat, \& Baltes, 1978-79; Hoyer, Labouvie, $\&$ Baltes, 1973). In this work, older adults received practice in three types of activities associated with responding in paper-and-pencil tests: cancellation, marking, and filling in answers. The assumption was that increments in speed of performing such activities, usually a necessary part of taking tests of intelligence, would have a direct and pronounced impact on the level of performance obtained when measuring intelligence by means of paper-and-pencil tests.

These precursor studies did not support the major hypothesis. Increasing the speed by which subjects were able to cancel, mark, or fill in answers was not a major determinant of scores on intellectual tests within the age range investigated and with regard to the test of intelligence studied. However, these early studies resulted in two by-products that continued to nurture our interest in the study of modifiability.

The first by-product was that speed of the test-taking skills could be increased markedly in older persons (as is true for younger adults, of course), although there was no transfer of this increase in speed to performance on tests of intelligence. The second finding concerned the magnitude of the retest gains observed in the samples studied. All participating groups demonstrated marked gains in tests of intelligence from pre- to posttest. In fact, the authors commented that "such strong retest gains were not anticipated... Both the participation in the pretest and the associated interactions with the experimenters, therefore, may have resulted in such strong general training effects that the specific training programs (involving speed of test-taking skills) did not produce any additional generalized effects on the variables employed" (Hoyer et al., 1973, p. 239).

On the basis of these findings, it seemed reasonable to shift the focus of intervention from speed in test-taking skills to more direct ways of modifying intellectual functioning per se. One major research project which addressed this question in a systematic and theoretically coherent fashion was the Penn State Adult Development and Enrichment Project (ADEPT). It started in 1975 and was conducted jointly by the first author and Sherry L. Willis (Baltes \& Willis, 1982). In 1981, Baltes initiated a similar project (Projekt Altersintelligenz = PRO-ALT) at the Max Planck Institute for Human Development and Education, Berlin, in collaboration with Freya Dittmann-Kohli and Reinhold Kliegl (Baltes, Dittmann-Kohli \& Kliegl, 1986).

The empirical part of both projects (ADEPT, PRO-ALT) consisted of a series of interrelated intervention studies that extended over varying portions of time, from approximately 1 month to nearly 2 years. Throughout, the focus was on the study of the range of intraindividual modifiability (plasticity) in fluid intelligence that can be effected by practice and training. The cluster of fluid intelligence was chosen as the target of intervention because it represents the domain of intelligence in which aging loss is most conspicuous, both theoretically and empirically (Cattell, 1971; Horn, 1970, 1982; Salthouse, 1985). 
The training strategies used in our intervention research are primarily educational in nature. They include two types: (a) self-guided practice and (b) trainerguided instructional programs geared towards the teaching of problem-solving skills relevant for adequate performance on tests of fluid intelligence. Assessment of practice and training effectiveness featured two dimensions of generalization: (a) transfer of training to a broad spectrum of intelligence, and (b) maintenance of training gains over time (Baltes \& Willis, 1982).

\section{Effects of Retest Practice and Self-Guided Learning}

One of the more surprising findings of the early work on the modifiability of speed of responding was the size of retest effects for tests of psychometric intelligence (Hoyer et al., 1973). To investigate this issue more systematically, Hofland, Willis, and Baltes (1981) conducted a study involving eight sessions of self-guided practice with intelligence tests. Two tests were administered, each representing one subability of fluid intelligence: figural relations and induction. Thirty older subjects (mean age: 69 years) participated in eight one-hour practice (retest) sessions distributed over approximately 1 month. At each session, the same tests were administered. No feedback on individual performance was given.

Figure 1 summarizes the outcome showing the mean percentage for correct solutions for each of the two fluid measures. Statistically, there is a continuous incremental trend in performance across the eight retest trials. Total improvement in mean scores on both measures is slightly more than one standard deviation. No apparent asymptote is reached after eight successive retest sessions.

The data were also analyzed for changes in test validity as a function of practice and for evidence on interindividual differences in performance trends. When correlating retest performance with a set of external marker tests of the broader domain of psychometric intelligence (reasoning, memory span, crystallized knowledge, and perceptual speed), there is very little evidence for a testing-related change in the validity of the two retests. Thus, in terms of correlational validity, what is measured at the eighth testing is similar to what the two tests measured at the beginning of the retest sessions.

Subsequently, we have continued to explore the question of the extent of cognitive gain that older adults are able to produce on their own, i.e., without experimenter-guided instruction. In a recent study (Baltes, Kliegl, \& DittmannKohli, in press), for example, older adults $(N=60$, mean age 74 ; age range 65-87) were given the opportunity to spend four times as much time on individual test items than is available under standard time conditions. Use of such a "power" condition was intended to examine further the question of levels of performance in tests of intelligence that could be reached by elderly subjects alone; i.e., by self-directed application of their own cognitive repertoire without assistance by an instructor.

When comparing the gains achieved by a simple time extension with training gains following experimenter-guided instruction in test-relevant cognitive skills in Baltes et al. (in press), the results supported further the conclusion of a sizeable reserve capacity. Simply having more time available permits older persons to solve as many test items (of all levels of difficulty) as are solved 


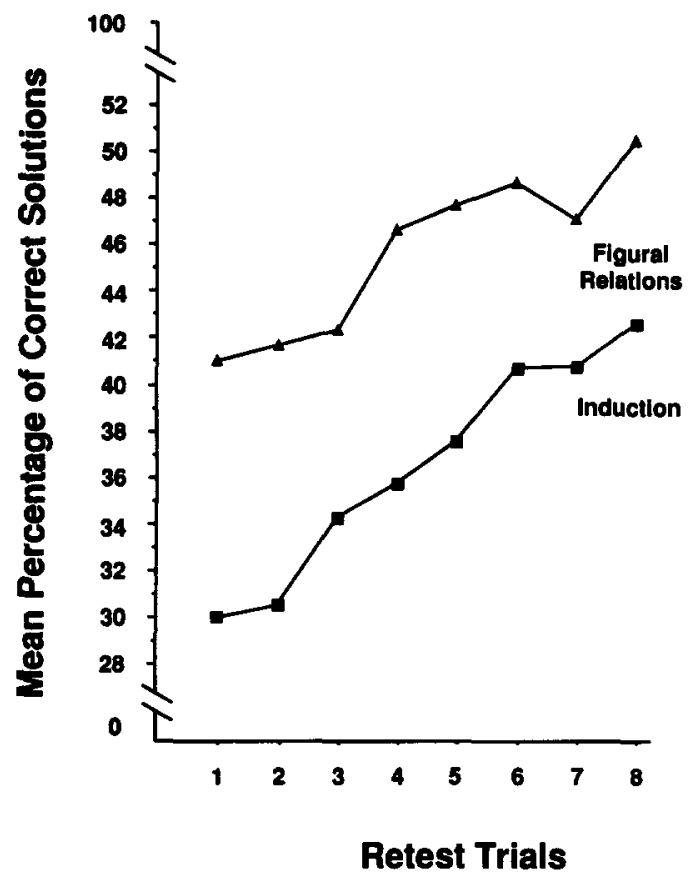

Fig. 1. Mean percentage of correct solutions across retest trials for tests of figural relations and induction. From Hofland, Willis, \& Baltes, 1981.

by subjects who had participated in instruction on the relevant cognitive skills by expert trainers (see below). The only departure from this pattern involves accuracy of performance when dealing with the most difficult items in a test. When solving the most difficult items, older adults in the self-guided practice condition make more mistakes than persons exposed to training from an expert, although they did achieve the same number of correct solutions.

In sum: These findings on retest gain and self-guided learning indicate that older persons are quite able to use cognitive skills already within their repertoire to improve performance significantly on tests of intelligence. This is clear evidence for plasticity or reserve capacity in old age.

\section{Guided Instruction in Cognitive Skills}

Direct instruction in the cognitive skills relevant for the solution of tests of fluid intelligence has been the second focus of our Phase 1 cognitive intervention work with the elderly. The general goal of this line of research has been the study of how direct training affects cognitive skills associated with fluid intelligence, in order to assess more fully the range and level of plasticity (reserve capacity) available to older adults.

As described in more detail in the first major summary publication (Baltes $\&$ Willis, 1982), the general design of the individual training studies usually 
included two additional features. First, attention was given to the breadth of transfer of training. Breadth or scope of cognitive training was assessed with a battery of transfer tests. Second, time maintenance of cognitive training was considered by administering follow-up tests. Most studies include follow-up studies covering up to 6 months after training.

Meanwhile, a fairly large number of such cognitive training studies have been reported in the literature (e.g., Baltes, Dittmann-Kohli, \& Kliegl, 1986; Baltes \& Willis, 1982; Blieszner, Willis, \& Baltes, 1981; Schaie \& Willis, 1986; Willis, Blieszner, \& Baltes, 1981). The pattern of results of this research is highly consistent. A recent study by Baltes et al. (1986) conducted at Berlin serves as an exemplar.

Subjects. The study sample $(N=204)$ in the Baltes et al. (1986) work consisted of 155 female and 49 male older adults (average age $=72$ years; range $=60-85$ years) from Berlin, West Germany. All of the subjects were volunteers and physically able to come to the laboratory. Reported subjective health was above average $(\mathrm{M}=3.7, \mathrm{SD}=.7$, on a five-point self-report scale). Average educational level (roughly comparable to U.S. information on educational history) was 11 years $(\mathrm{SD}=2.7)$. When comparing level of intellectual performance on equivalent tests with the U.S. samples from rural Pennsylvania (e.g., Hofland et al., 1981), the Berlin sample scored about 0.5 SD higher. The Berlin sample was also slightly more heterogeneous in intellectual performance.

Procedure and Design. The experimental-control group design involved three main parts: a pretest, cognitive training, and three posttests administered 1 week, 1 month, and 6 months after training. The test batteries (Table 1) given at pretest and at all posttests were identical and consisted of eight subtests. These subtests covered a broad range of psychometric intelligence as defined by the theory of fluid-crystallized intelligence (Cattell, 1971; Horn, 1982). Tests were ordered along a transfer of training continuum representing the degree of similarity of the individual tests to the target domain used in cognitive (ability) training.

Participants were randomly assigned to a cognitive training and a retestpractice control group. The cognitive training program consisted of 10 sessions $(1 \mathrm{hr}$. each) distributed over 1 month. Five consecutive sessions dealt with the fluid ability of figural relations, and the other five with induction.

Training Program. The cognitive training programs were developed through task analysis of the items and rules contained in two established subtests of fluid intelligence. Specifically, tests of figural relations and induction served as markers of the domain of fluid intelligence. None of the items used in training were identical in content to the ones constituting the standardized test forms used to assess training effectiveness.

The training program, conducted in small groups of 6 to 12 participants, focused on helping subjects to identify the rules and concepts derived from a content analysis of the markers and to use them in solving the types of problems associated with figural relations and induction. The tutor and participating subjects modeled how to identify and use the rules; subjects practiced employing these strategies. Feedback and discussion about these strategies, as 


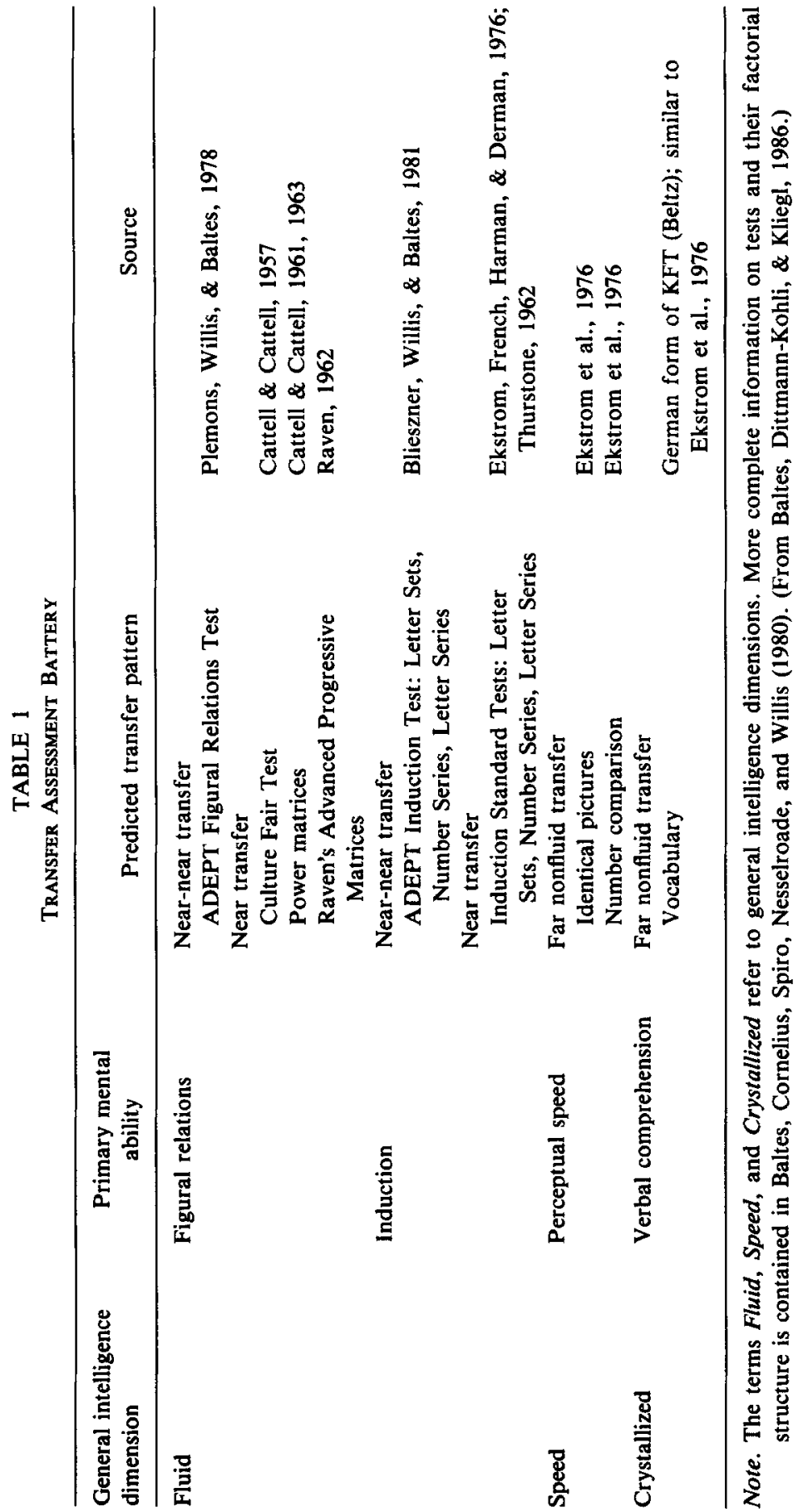


well as about the possibility of using alternate strategies, followed. Further information about the training program is contained in Blieszner et al. (1981) and Willis et al. (1981).

Training Effects and Pattern of Transfer. In this study, as was true for previous ones, the statistical results (not reported here) displayed a pattern that was clear and consistent with the hypotheses (see Figure 2). First, there was definite improvement following cognitive training. On near-transfer measures, the amount of training gain is about $1 / 2$ to $2 / 3$ of a standard deviation. Second, training gains were maintained for the entire time period (six months) studied. Thus, the results of this study demonstrated that older adults do have the reserve capacity to benefit from guided cognitive practice even in that intellectual domain (fluid intelligence), which in the normal course of aging is subject to loss.

Two additional findings are noteworthy. The first involves the fact of transfer of training. Note that the studies of retest gain reported in an earlier section of this paper were based on the same items being practiced repeatedly. In the present instance, since the items used for training and assessment were different, the training gain included transfer to a somewhat novel set of items.

The spectrum of transfer to tasks not practiced during cognitive training, however, was limited. In this study, as in earlier ones, transfer was restricted to such tests of fluid intelligence that were within a narrow band surrounding the two tests (figural relations, induction) used for the development of the training program. Such a limited spectrum of "within-ability" transfer makes apparent that psychometric intelligence and the associated systems of skills and knowledge represent a heterogeneous domain. One should not expect, therefore, cognitive training programs to affect the entire spectrum of the domain of intelligence unless they are designed such that they are aimed (in scope and investment) at broad spectrum effects.

A second finding of particular interest concerns level of difficulty and accuracy of the performance reached after cognitive training. In Baltes et al. (1986), it is also reported that experimenter-guided training produces performances that display a higher level of difficulty and accuracy than was evident prior to training. Level of difficulty of cognitive performance was based on the percentage of subjects who were able to solve each test item under nontrained conditions. Accuracy was estimated by the number of errors which subjects made when solving all items of a test. Because trained subjects were able to solve more difficult items and reduce their error rate, we can conclude that the reserve capacities of older adults include the potential to reach "higher" levels of cognitive difficulty and to refine their cognitive system so that it becomes more efficient (accurate).

\section{Implications and Possible Misinterpretations}

Phase 1 research as a whole demonstrates that many older individuals have a sizeable reserve capacity of intelligence. The process of cognitive aging, therefore, is not merely a passive process of decline. It includes (a) the possibility of reactivation of knowledge and skills available in earlier times of life as well as (b) the acquisition of new knowledge and skills. 


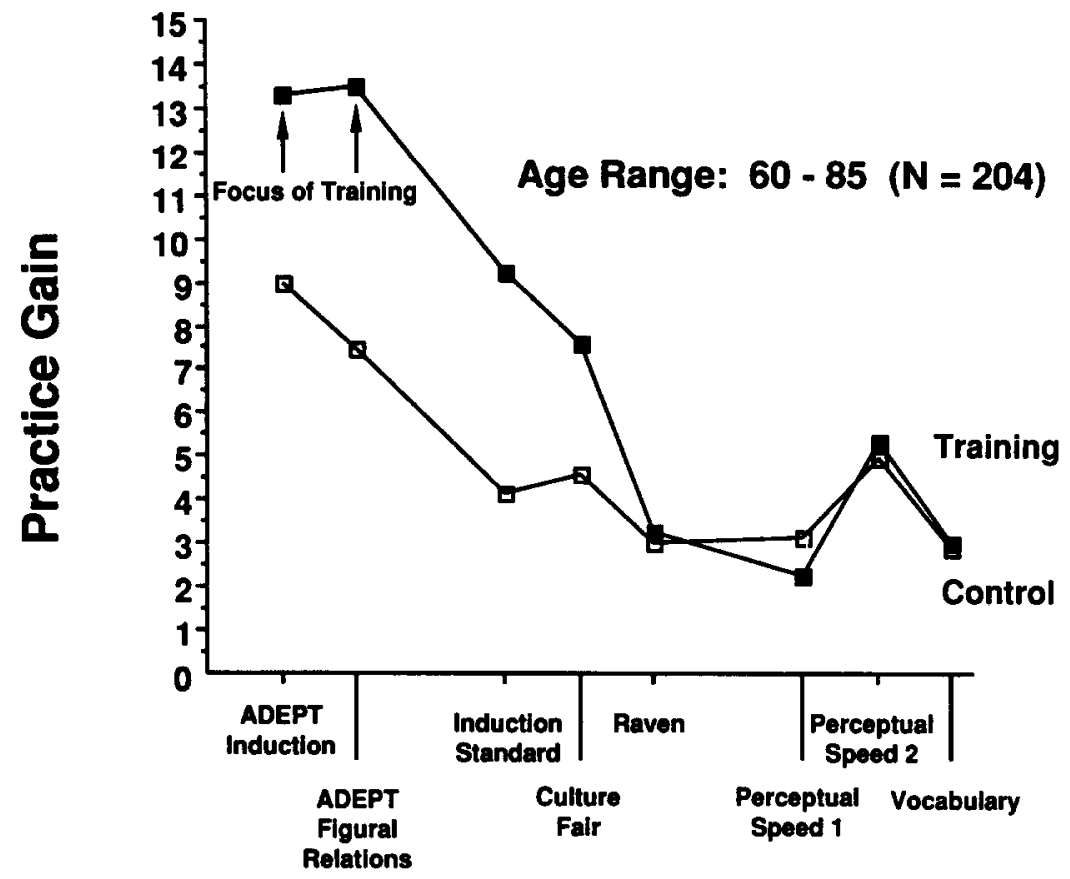

\section{Transfer Tests}

Fig. 2. Retest and training gains of training and control groups in transfer tests of intelligence averaged across three posttests ( 1 week, 1 month, and 6 months following training). Tests are ordered on a continuum of decreasing similarity to training focus: fluid, 1-5; perceptual speed, 6-7; crystallized, 8. From Baltes, Dittmann-Kohli, \& Kliegl, 1986.

When comparing the magnitude of training gains achieved in our intervention work with the magnitude of "natural" aging loss reported in long-term longitudinal research on this age range (e.g., age 50 until age 70; Schaie, 1983), the amount of training gain found is as large as the natural aging loss. Using subjects observed longitudinally, Schaie and Willis (1986) have supported this conjecture. When participating as older adults in a cognitive training program of the kind described here, many older adults were able to return to the same level of IQ-test performance that they had shown 14 years earlier.

To prevent possible misinterpretations of our research on intellectual plasticity (reserve capacity) in tests of fluid intelligence in the elderly, some caveats are necessary. The results of our cognitive training studies do not imply the following three conclusions (Baltes \& Kliegl, 1986). First, that older adults profit more from intelligence training than young adults. As there are no good age-comparative studies on training gain, no definite knowledge about this question is available. Second, that the cognitive training programs raised the level of intelligence as a whole to the level shown in younger adulthood. In 
fact, the gain was demonstrated only for the specific subabilities trained. Thus, as is true for much other cognitive training research, transfer of training was fairly narrow.

The third possible misinterpretation would be that all aging individuals display the plasticity reported here. We do not know the subject generality of our findings. While we do believe that most elderly individuals up to age 80 or so are capable of major training benefits, we need to re-emphasize that our samples are clearly biased towards the healthy elderly and that they most likely do not include persons who suffer from brain-related diseases, such as senile dementia of the Alzheimer type. Certainly, there are aging-related disease groups for which we would not expect the magnitude of plasticity demonstrated by our elderly subjects (M. Baltes \& Kindermann, 1985; Baltes \& Kliegl, 1986).

\section{Phase 2: Testing-the-Limits of Cognitive Reserve Capacity (Plasticity)}

The research conducted during Phase 1 demonstrated a sizeable degree of plasticity (reserve capacity) of intellectual performance in many older persons. What about limits to plasticity? Would the elderly reach levels of performance following extended practice and cognitive engineering that are comparable to those obtained by young adults (Baltes \& Willis, 1982; Baltes et al., 1984; Kliegl \& Baltes, 1987)? The goal of Phase 2 research was to explore the existence of age-graded changes in limits of plasticity in cognitive functioning.

\section{Why Age Differences at Limits?}

There are several reasons why we chose to focus on limits to plasticity. A first is methodological. We were impressed with the methodological strategies of "stress testing" advanced in biology and medicine (Coper, Jänicke, \& Schulze, 1986; Fries \& Crapo, 1981). Stress tests are designed to test the adaptive fitness of a system in a more refined manner than would be possible under one-time, standard conditions within the "normal" (habitual) range of performance. In psychology, similar arguments have been advanced by researchers interested in pathological and developmental assessment. An especially promising methodology called "Testing-the-Limits" has been offered to delineate the "zone of proximal development" or the "latent potential" that individuals hold (M. Baltes \& Kindermann, 1985; Guthke, 1982; Kliegl \& Baltes, 1987; Schmidt, 1971; Wiedl, 1984).

The second reason for our interest in limits of performance was theoretical. It became increasingly clear to us that the ultimate interest of gerontological researchers was in estimating through assessment of "phenotypic" performance the inherent biological ("genotypic") capacity of an organism. In such a line of reasoning, observed performance is but a way-station toward the estimation of what is truly of interest: latent performance potentials.

In the usual age comparisons of cognitive functioning, however, there are a myriad of factors that make it hard to consider age differences in performance as age differences in potential or latent capacity (Salthouse, 1985; Willis 
\& Baltes, 1980). Young and older adults differ in many performance-related factors. As a consequence, there is no simple mapping from levels of performance to levels of potential or latent capacity. To deal with the many possible confounds, we attempted to formulate a conceptual framework within which the goal of the search for latent potential could be realized (Baltes et al., 1984; Kliegl \& Baltes, 1987). This framework is described in Table 2.

In Table 2, three levels of capacity or plasticity are distinguished: (1) baseline performance, (2) baseline reserve capacity, and (3) maximum or developmental reserve capacity. The research objective of Phase 2 is to unravel successively the range of these three levels of plasticity or reserve capacity.

To accomplish this objective, we reconsidered and elaborated the methodological arguments for the use of stress tests and testing-the-limits methodology. Our goal was to use this methodology in order to successively explore the range of cognitive reserve capacity described in Table 2 . Specifically, we conceptualized testing-the-limits as a general research strategy that would permit the construction and testing of high levels of performance (Kliegl \& Baltes, 1987). Construction of high levels (possibly of limits) of performance is reached by means of extensive practice in, and cognitive engineering of, a skill. Further testing of the limits is, then, achieved by systematic variation of levels of difficulty.

The final goal of this strategy of testing-the-limits research is to obtain knowledge about what individuals could attain under "near-optimal" conditions of development. We take such near-optimal performances as an estimate of maximum reserve capacity. While the cognitive training work of Phase 1 attended to plasticity (mostly in the normal range of functioning), testing-the-limits work associated with Phase 2 focused jointly on plasticity and the limits on plasticity. The following study illustrates this approach.

TABLE 2

On Reserve Capacity (Plasticity) and Testing-the-Limits

Objective $\quad$ Testing-the-Limits is a strategy aimed at estimation of the range of cur-
rent and future reserve capacity

Three tiers of reserve capacity (plasticity)

Baseline performance

Assessment of performance under standardized conditions without intervention

Current maximum performance

Assessment of current maximum performance potential (competence) by strategies aimed at optimization through variation of performance factors (context, instruction, motivation, etc.)

Developmental Reserve Capacity

Assessment of future performance potential by means of developmentenhancing interventions

Note. Modified after Baltes, Dittmann-Kohli, and Dixon, 1984; and Kliegl and Baltes, 1987. 


\section{Age Differences in Memory Operations near Limits}

Research conducted by Kliegl, Smith, and Baltes (1986; see also Smith, Kliegl, \& Baltes, 1987) represents our initial use of testing-the-limits; its focus is on certain memory operations, which are also a part of fluid intelligence. Specifically, the memory operations selected involve the ability for mental imagery as measured in the mnemonic technique called the method of loci (Bower, 1970; Kliegl \& Baltes, 1987). In the method of loci, subjects (a) learn a sequence of locations and (b) practice forming mental images linking the memory material (such as words) to the locations. Table 3 illustrates the procedure.

With practice, most subjects can become quite expert in the use of the method of loci in encoding and retrieving memory material. Most healthy persons, in fact, can reach levels of performance that would qualify them as memory experts. In the final analysis, how well subjects can perform is a function of how effectively they can generate new and vivid images for memory material, how fast they can associate (connect) the images with the locations, and how well they can locate and decode the images at the time of retrieval.

Figure 3 summarizes the findings as reported in Kliegl et al. (1986) and Smith et al. (1987). As expected, both plasticity and limits to plasticity are evident. Plasticity in memory is demonstrated by the fact that all subjects - young and old - are able to raise their levels of memory performance from recalling 4-6 words to recall of much longer strings such as 20 words. This increased level of performance reflects the effects of practice and cognitive engineering.

Limits to plasticity are evident because individuals are unable to use the acquired memory expertise (method of loci) when the task is made more and more difficult. In this research, difficulty is increased by raising the presentation rates of the lists of words ( $20 \mathrm{sec}$, $10 \mathrm{sec}$., $4 \mathrm{sec}$., etc.). At fast speeds of presentation, the differences between young and old subjects are magnified to such a degree that there is barely any overlap between distributions of old

TABLE 3

METHOD OF LOCI

\begin{tabular}{ll}
\hline \multicolumn{1}{c}{ Strategy } & \multicolumn{1}{c}{ Illustration } \\
\hline 1. Acquire a fixed sequence of locations & $\begin{array}{l}\text { Radio tower } \\
\text { Berlin Wall } \\
\text { Egyptian Museum }\end{array}$ \\
& $\begin{array}{l}\text { Café Kranzler } \\
\text { Rooster } \rightarrow \text { A rooster impaled on the } \\
\text { tip of the radio tower } \\
\text { Cake } \rightarrow \text { cake enclosed in the } \\
\text { barbed wire of the Berlin Wall } \\
\text { Radio tower } \rightarrow \text { image } \rightarrow \text { rooster }\end{array}$ \\
$\begin{array}{l}\text { 2. For each memory stimulus, form a mental } \\
\text { image } \\
\text { stimulus }\end{array}$ & $\begin{array}{l}\text { At time of recall, retrieve mental image and } \\
\text { decode memory stimulus }\end{array}$ \\
\hline
\end{tabular}




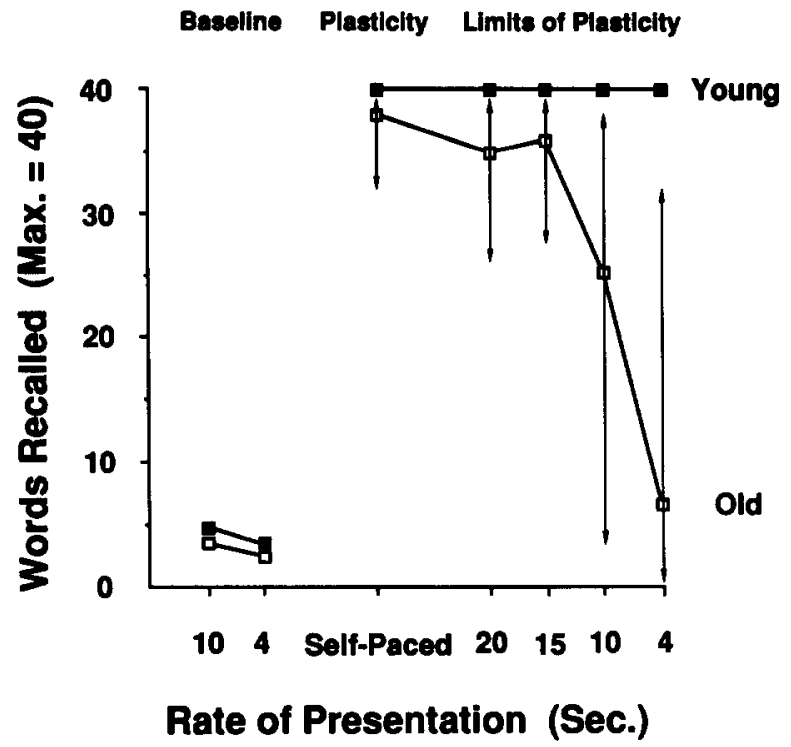

Fig. 3. Expertise in the Method of Loci: Mean and range of recall for 40 words in normal young and superior old subjects. (Adapted from Kliegl, Smith, \& Baltes. 1986).

and young adults of comparable IQ. In other words, as we move from the normal range of functioning to maximum levels of functioning, age differences are amplified.

The study described testifies to the usefulness of testing-the-limits methodology for identifying tiers of reserve capacity. How close the limits of performance reached are to the "final" levels of maximum reserve capacity is an open question. In the present study, final limits in the use of the method of loci probably were not reached. It is more likely that they were reached in a subsequent study conducted by Kliegl (1987), which involved 120 rather than 25-30 trials of training in the method of loci. In this study, young and old subjects displayed performances that seemed close to an asymptote. Despite further practice, no further improvement was apparent. (Age differences near performance limits were also clearly apparent and robust.)

Phase 2 research on the range of plasticity for cognitive aging is still in its infancy. Thus, the evidence obtained in a few studies has not yet been tested for its robustness and generalizability. The data available thus far, however, point consistently in the same direction. On the one hand, the evidence for sizeable plasticity is further strengthened. Even in domains where natural aging loss is paramount, such as in "fluid" memory, many older persons are capable of new performance levels that approximate what is usually called a high-level expertise. There is indeed much latent reserve capacity. On the other hand, the evidence seems equally strong that, near limits, age differences are (a) magnified and (b) robust to such a degree that they approximate irreversibility. 
In sum: Considering only Phase 1 research, with its primary focus on plasticity within the normal range of cognitive functioning, would result in an incomplete report on the nature of the aging of intelligence. Phase 2 research shows that at limits, at least for the cognitive tasks studied, there is definite aging loss. Whether such aging loss at limits is relevant in everyday cognitive behavior is another question deserving further investigation.

\section{SUMMARY}

The intervention work presented here - because of its programmatic commitment to the exploration of conditions and variations of cognitive aging has pushed our knowledge about the nature of the aging of intelligence beyond what one observes in the natural context of everyday life. The resulting evidence has contributed to a more differentiated view than prevailed heretofore. This changed view has implications for theory and clinical practice.

On the level of theory, the nature of the aging of intelligence needs to be seen as an ongoing dynamic between growth and decline (Baltes, 1987; Baltes \& Kliegl, 1986; Smith, Dixon, \& Baltes, 1989). The possibility of growth is evident in the fact that most elderly possess a sizeable amount of reserve capacity which can be activated for new learning, refining, and elaborating what is already available. The older organism is not a system whose primary feature is passive decay. This sizeable reserve capacity notwithstanding, however, the aging process entails also a definite loss in the range of plasticity; reserve capacity is reduced in magnitude. As a consequence, the adaptivity of the cognitive system (Coper et al., 1986; Kliegl \& Baltes, 1987) of older persons is likely to be smaller in such parameters as scope, speed, and maximum level.

What about implications of this view of a dynamic between growth and decline for models of personal growth and clinical practice? Table 4 summarizes one model of cognitive aging that speaks to the dynamic between growth and decline and its augmented manifestation at limits of performance. A prototypical mechanism of "successful" aging is delineated in Table 4 which illustrates how the dual facts of sizeable reserve capacity and limits to reserve capacity can be united for the purpose of effective adaptation to old age.

The prototypical mechanism of effective adaptation described in Table 4 is called "selective optimization with compensation" (M. Baltes, 1987; Baltes \& Baltes, 1980; P. Baltes, 1987). Selective optimization refers to the effective use of a reduced scope of plasticity (reserve capacity) for a select (less numerous) number of domains of cognitive life. In other words, it is possible to optimize one's cognitive skills through practice, such that a high level of efficacy can be maintained (or acquired) in the smaller number of domains selected. The compensatory component of the mechanism of adaptation involves special effort and the search for alternate routes. Such compensatory behavior is necessary if and when the normal or primary components necessary for solving a problem are not available anymore at the required level of skill or efficacy.

Salthouse (1984) has conducted a study which in our view can be used to illustrate the effective use of the adaptive mechanism of selective optimization with compensation in advanced age. Salthouse compared the way good old 
TABLE 4

Selective Optimization with Compensation: A Process Prototypical of Adaptive Life-Span DeVelopment of Cognitive Functioning

A general feature of life-span development is an age-related increase in specialization (selection) of motivational and cognitive resources and skills.

There are two main features of the aging of cognitive functions:

(a) The reserve capacity for peak or maximum performances in fluid functioning (mechanics of intelligence) is reduced.

(b) Some procedural and declarative knowledge systems (pragmatics of intelligence) can continue to evolve and function at peak levels.

When and if limits (thresholds) of capacity are exceeded during the course of aging for a given individual, the following developmental consequences result:

(a) Increased selection (channeling) and further reduction of the number of high efficacy domains.

(b) Development of compensatory and/or substitute mechanisms.

Note. Modified after Baltes and Baltes, 1980 (see also Dixon and Baltes, 1986).

and young typists produced their high (expert) levels of typing performance. The finding was that expert older typists have definitely a slower reaction time than younger typists when asked to type individual characters (letters). They compensate for this slower reaction time, however, by using longer forward spans when reading the text to be typed. As a consequence, slower reaction time does not interfere with expert performance in the natural setting of typists. (Incidentally, what is not clear in Salthouse's study is whether older typists actually "develop" the compensatory strategy of forward reading or whether they simply use a component that is available both to the young and the old typists).

The mechanism of selective optimization with compensation may be of use as a mental scenario and directional agenda for practitioners working with the elderly. The scenario and mental map emphasize the search for the continued potential of older persons in the face of reduced reserves (or increased vulnerabilities). At the same time, the proposed mechanisms of "successful aging" suggest a careful analysis of the individual's life situation. Whereas the mechanism of selective optimization with compensation is postulated to be a universal mechanism of successful aging, its specific manifestation is likely to vary markedly in content and form from person to person depending on each person's history, values, and life circumstances. How creative the individual's strategies of selective optimization with compensation can be is persuasively exemplified in an autobiographical observation by B. F. Skinner (1983) dealing with his own mastery of old age.

\section{REFERENCES}

Baltes, M. M. (1987). Erfolgreiches Altern als Ausdruck von Verhaltenskompetenz und Umweltqualität. In C. Niemitz (Ed.), Der Mensch im Zusammenspiel von Anlage und Umwelt. Frank- 
furt: Suhrkamp.

Baltes, M. M., \& Kindermann, T. (1985). Die Bedeutung der Plastizität für die klinische Beurteilung des Leistungsverhaltens im Alter. In D. Bente, H. Coper, \& Kanowski (Eds.), Hirnorganische Psychosyndrome im Alter: Vol. 2. Methoden zur Objektivierung pharmakotherapeutischer Wirkung (pp. 171-184). Berlin: Springer-Verlag.

Baltes, P. B. (Ed.). (1973). Strategies for psychological intervention in old age. The Gerontologist, 13, 4-38.

Baltes, P. B. (1987). Theoretical propositions of life-span developmental psychology: On the dynamics between growth and decline. Developmental Psychology, 23, 611-626.

Baltes, P. B., \& Baltes, M. M. (1980). Plasticity and variability in psychological aging: Methodological and theoretical issues. In G. E. Gurski (Ed.), Determining the effects of aging on the central nervous system (pp. 41-66). Berlin: Schering AG.

Baltes, P. B., Cornelius, A. S., Spiro, A., Nesselroade, J. R., \& Willis, S. L. (1980). Integration versus differentiation of fluid/crystallized intelligence in old age. Developmental Psychology, $16,625-635$.

Baltes, P. B., Dittmann-Kohli, F., \& Dixon, R. (1984). New perspectives on the development of intelligence in adulthood: Toward a dual-process conception and a model of selective optimization with compensation. In P. B. Baltes \& O. G. Brim, Jr. (Eds.), Life-span development and behavior (Vol. 6, pp. 33-76). New York: Academic Press.

Baltes, P. B., Dittmann-Kohli, F., \& Kliegl, R. (1986). Reserve capacity of the elderly in agingsensitive tests of fluid intelligence: Replication and extension. Psychology and Aging, l, 172-177.

Baltes, P. B., \& Kliegl, R. (1986). On the dynamics between growth and decline in the aging of intelligence and memory. In K. Poeck, H. J. Freund, \& H. Gänshirt (Eds.), Neurology (pp. 1-33). Heidelberg: Springer.

Baltes, P. B., Kliegl, R., \& Dittmann-Kohli, F. (in press). On the locus of training gains in research on the plasticity of fluid intelligence in old age. Journal of Educational Psychology.

Baltes, P. B., \& Labouvie, G. V. (1973). Adult development of intellectual performance: Description, explanation, modification. In C. Eisdorfer \& P. Lawton (Eds.), The psychology of adult development and aging. Washington DC: American Psychological Association.

Baltes, P. B., \& Schaie, K. W. (1976). On the plasticity of intelligence in adulthood and old age: Where Horn and Donaldson fail. American Psychologist, 31, 720-725.

Baltes, P.B., \& Willis, S. L. (1982). Plasticity and enhancement of intellectual functioning in old age: Penn State's Adult Development and Enrichment Project (ADEPT). In F.I.M. Craik \& S. E. Trehub (Eds.), Aging and cognitive processes (pp. 353-389). New York: Plenum Press.

Blieszner, R., Willis, S. L., \& Baltes, P. B. (1981). Training research in aging on the fluid ability of inductive reasoning. Journal of Applied Developmental Psychology, 2, 247-265.

Bower, G. H. (1970). Analysis of a mnemonic device. American Scientist, 58, 496-510.

Cattell, R. B. (1971). Abilities: Their structure, growth, and action. Boston: Houghton Mifflin.

Cattell, R. B., \& Cattell, A.K.S. (1957). Test of " $g$ ": Culture Fair (Scale 2, Form A). Champaign, IL: Institute for Personality and Ability Testing.

Cattell, R. B., \& Cattell, A.K.S. (1961). Measuring intelligence with the Culture Fair tests: Manual for scales 2 and 3. Champaign, IL: Institute for Personality and Ability Testing.

Cattell, R. B., \& Cattell, A.K.S. (1963). Test of "g": Culture Fair (Scale 3, Form A). Champaign, IL: Institute for Personality and Ability Testing.

Coper, H., Jänicke, B., \& Schulze, G. (1986). Biopsychological research on adaptivity across the life span of animals. In P. B. Baltes, D. L. Featherman, \& R. M. Lerner (Eds.). Life-span development and behavior (Vol. 7, pp. 207-232). Hillsdale, NJ: Lawrence Erlbaum.

Denney, N. W. (1979). Problem-solving in later adulthood: Intervention research. In P. B. Baltes \& O. G. Brim, Jr. (Eds.), Life-span development and behavior (Vol. 2, pp. 37-66). New York: Academic Press. 
Denney, N. W. (1984). A model of cognitive development across the life span. Developmental Review, 4, 171-191.

Dixon, R. A., \& Baltes, P. B. (1986). Toward life-span research on the functions and pragmatics of intelligence. In R. J. Sternberg \& R. K. Wagner (Eds.), Practical intelligence: Nature and origins of competence in the everyday world (pp. 203-234). New York: Cambridge University Press.

Ekstrom, R. B., French, J. W., Harman, H., \& Derman, D. (1976). Kit of factor-referenced cognitive tests, 1976 revision. Princeton, NJ: Educational Testing Service.

Fries, J. F., \& Crapo, L. M. (1981). Vitality and aging. San Francisco, CA: Freeman \& Co.

Guthke, J. (1982). The learning test concept - an alternative to the traditional static intelligence test. The German Journal of Psychology, 6, 306-324.

Hofland, B., F., Willis, S. L., \& Baltes, P. B. (1981). Fluid intelligence performance in the elderly: Intraindividual variability and conditions of assessment. Journal of Educational Psychology, 73, 573-586.

Horn, J. L. (1970). Organization of data on life-span development of human abilities. In L. R. Goulet \& P. B. Baltes (Eds.), Life-span developmental psychology: Research and theory (p. 423-466). New York: Academic Press.

Horn, J. L. (1982). The theory of fluid and crystallized intelligence in relation to concepts of cognitive psychology and aging in adulthood. In F.I.M. Craik \& S. E. Trehub (Eds.), Aging and cognitive processes (pp. 847-870). New York: Plenum Press.

Hoyer, F. W., Hoyer, W. J., Treat, N. J., \& Baltes, P. B. (1978-79). Training response speed in young and elderly women. International Journal of Aging and Human Development, 9, 247-253.

Hoyer, W. J., Labouvie, G. V., \& Baltes, P. B. (1973). Modification of response speed deficits and intellectual performance in the elderly. Human Development, 16, 233-242.

Kastenbaum, R. (1968). Perspectives on the development and modification of behavior in the aged: A developmental-field perspective. The Gerontologist, 8, 280-283.

Kausler, D. H. (1982). Experimental psychology of human aging. New York: Wiley.

Kliegl, R. (July, 1987). Formation of expert knowledge in a mnemonic skill: Twelve case studies of young and old adults. Paper presented at the IX Biennial Meeting of the International Society for the Study of Behavioural Development, Tokyo, Japan.

Kliegl, R., \& Baltes, P. B. (1987). Theory-guided analysis of mechanisms of development and aging through testing-the-limits and research on expertise. In C. Schooler \& K. W. Schaie (Eds.), Cognitive functioning and social structure over the life course (pp. 95-119). Norwood, NJ: Ablex.

Kliegl, R., Smith, J., \& Baltes, P. B. (1986). Testing-the-limits, expertise, and memory in adulthood and old age. In F. Klix \& H. Hagendorf (Eds.), Human memory and cognitive capabilities: Mechanisms and performances (pp. 395-407). Amsterdam: North Holland.

Labouvie, G., Hoyer, W. F., Baltes, M. M., \& Baltes, P. B. (1974). An operant analysis of intelligence in old age. Human Development, 17, 259-272.

Labouvie-Vief, G. (1977). Adult cognitive development: In search of alternative interpretations. Merrill-Palmer Quarterly, 23, 227-263.

Labouvie-Vief, G. (1985). Intelligence and cognition. In J. E. Birren \& K. W. Schaie (Eds.), Handbook of the psychology of aging (2nd ed., pp. 500-530). New York: Van Nostrand Reinhold.

Plemons, J. K., Willis, S. L., \& Baltes, P. B. (1978). Modifiability of fluid intelligence in aging: A short term longitudinal training approach. Journal of Gerontology, 33, 224-231.

Raven, J. C. (1962). Advanced progressive matrices, Set II, 1962 revision. London: H. K. Lewis \& Co. Ltd.

Salthouse, T. A. (1984). Effects of age and skill in typing. Journal of Experimental Psychology: General, 113, 345-371.

Salthouse, T. A. (1985). A theory of cognitive aging. Amsterdam: North Holland. 
Schaie, K. W. (Ed.). (1983). Longitudinal studies of adult psychological development. New York: The Guilford Press.

Schaie, K. W., \& Willis, S. L. (1986). Can adult intellectual decline be reversed? Developmental Psychology, 22, 223-232.

Schmidt, L. R. (1971). Testing-the-limits im Leistungsverhalten: Möglichkeiten und Grenzen. In E. Duhm (Ed.), Praxis der Klinischen Psychologie (Vol. 2, pp. 9-29). Göttingen: Hogrefe.

Skinner, B. F. (1983). Intellectual self-management in old age. American Psychologist, 38, 239-244.

Smith, J., Dixon, R. A., \& Baltes, P. B. (1989). Expertise in life planning: A new research approach to investigating aspects of wisdom. In M. L. Commons, J. D. Sinnott, F. A. Richards, \& C. Armon (Eds.), Beyond formal operations II: Comparisons and applications of adolescent and adult developmental models. New York: Praeger.

Smith, J., Kliegl, R., \& Baltes, P. B. (1987). Testing-the-limits and the study of age differences in cognitive plasticity: The sample case of expert memory. Unpublished manuscript.

Thurstone, T. G. (1962). Primary mental abilities, grades 9-12, 1962 revision. Chicago, IL: Science Research Associate.

Wiedl, K. H. (1984). Lerntests: Nur Forschungsmittel und Forschungsgegenstand? Zeitschrift für Entwicklungspsychologie und Pädagogische Psychologie, 16, 245-281.

Willis, S. L. (1985). Towards an educational psychology of the adult learner. In J. E. Birren \& K. W. Schaie (Eds.), Handbook of the psychology of aging (2nd ed., pp. 818-847). New York: Van Nostrand Reinhold.

Willis, S. L., \& Baltes, P. B. (1980). Intelligence and cognitive ability. In L. W. Poon (Ed.), Aging in the 1980's: Psychological issues (pp. 260-272). Washington, DC: American Psychological Association.

Willis, S. L., Blieszner, R., \& Baltes, P. B. (1981). Intellectual training research in aging: Modification of performance on the fluid ability of figural relations. Journal of Educational Psychology, $73,41-50$.

NOTE: Figures from Journal of Educational Psychology, 1981, 73 and Psychology and Aging, 1986, 1. Copyright (1981) and (1986) by the American Psychological Association. Reprinted by permission of the publisher.

ReCEnED: August 17, 1987

Final ACCEPTANCE: December 1, 1987 